\title{
Addiction to automatic negative thoughts: $A$ perspective from rational emotive behaviour therapy
}

\begin{abstract}
In the context of psychotherapy there is a huge amount of people complaining about being addicted to their own thoughts especially to automatic negative thoughts that are perceived by the person as a cognitive compulsion impossible to avoid. Rational Emotive Behavior Therapy teaches how to detect this kind of mental habit and gives us strategies to overcome it by changing the irrational beliefs that are underlying it. Observing, disputing and changing these irrational beliefs using cognitive, emotional and behavioral tactics allow people to live with serenity and to achieve cognitive, emotional and behavioral goals.
\end{abstract}

Keywords: cognitive addiction, automatic negative thoughts, rational emotive behaviour therapy, psychotherapy
Volume 3 Issue 4 - 2017

\author{
Montse Rovira \\ Albert Ellis Institute, USA
}

Correspondence: Montse Rovira, Licensed Psychologist, Associate Fellow and International Supervisor of Cognitive Behavior Therapy and Rational Emotive Behavior Therapy of the Albert Ellis Institute, New York, USA, Jos $\tilde{A} \odot$ del Toro, 6, A I 100 I Cadiz Spain, Tel +34606369547, Email trecseo@gmail.com

Received: May 29, 2017 | Published: May 3I, 2017

\section{Introduction}

In the context of psychotherapy there is a huge amount of people complaining about being addicted to their own thoughts. "I just can't stop thinking this way about it" is a common lament in the psychologists' office. Whatever would be the issue underlying the demand for psychological help most people declare to be incapable to stop thinking in a limiting way that conducts them to feel unhealthy emotions. These unhealthy emotions use to be the first reason for clients to start therapy "I feel depressed", and the incapability to control their thoughts is the next difficulty they want to treat since they experience it as a sort of cognitive addiction.

Albert Ellis the founder of Rational Emotive Behavioral Therapy created the "ABC model" to explain how people disturb themselves. In this model "A" stands for adversity, "C" stands for the emotional consequence, and "B" stands for the beliefs about it. For example, according with this model a person who is involved in a process of divorce may feel depressed about it if the belief is "I shouldn't be living this situation in my life". What the ABC model explains is that what makes us feel in a certain way is not the circumstance itself but the way we think about it which is our perspective of the event. According with this personal evaluation of the adversity we produce thoughts that may help us to overcome the situation or not.

Being addicted to the own thoughts is something that clients have to overcome by acquiring the ability to identify the content of their way of thinking, which is the first step for a cognitive change. Rational Emotive Behavior Therapy encourages people to act as a detective, looking for the thoughts that appear automatically, observing what they are saying, and being aware that they are only a mindset built with irrational beliefs that may be changed. ${ }^{1}$ To identify irrational beliefs and then challenge and change them for rational beliefs means to develop a flexible way of thinking that will enable people to achieve their goals.

When someone is mentally harassed with thoughts around an event such as a divorce (continuing with the example) it can be realistic to feel a negative emotion. Changing the addiction to think in a negative way does not mean to feel positive emotions about it or feel not emotion at all. It is no realistic pretending to feel happiness in front of a sad situation and it is important to understand that negative emotions are not bad just because they are negative. ${ }^{2}$ In REBT we talk about healthy and unhealthy negative emotions and this is the question: knowing how to move from an unhealthy negative emotion to a healthy negative one is the key to live the situation applying the best strategies to overcome it.

From the psychological view human beings have three interlinked levels: cognitive, emotional and behavioral. In the cognitive level we move ahead or stay stuck depending on our beliefs. Healthy beliefs help us to achieve our goals while unhealthy beliefs debilitate us and maintain us involved in an unhealthy range of feelings. Beliefs are our view of the reality, the way we see the world, others and ourselves. Automatic thoughts are the way in which we internally express our beliefs. So we could say that trough out the thoughts we are aware of what we think, but not always have the same awareness of which are the beliefs underpinning these thoughts. The corner stone is the emotional level as far as it gives us the clue to find out what is wrong in the cognitive level that pushes us to feel miserable. When we have healthy beliefs we feel healthy emotions. Healthy emotions and healthy beliefs contribute to healthy behavior. Healthy behavior and healthy emotions also conduct us to think in a creative way and solve our problems successfully.

\section{Mind captivity?}

You are listening to music, reading your favourite novel, or enjoying a walk, it does not matter whatever you choose to spend a relaxation time and then something comes to your mind without your permission. It is an automatic thought carrying you beyond the present. After some time you become aware that you are not listening to the music although you haven't stop hearing it. Maybe you haven't stop reading but you are completely missed from the read. You have arrived to your destiny but you don't know the route you did. You've been captured by your thoughts and you feel that you can't help it. These thoughts are materialized in two common forms: images and words. They appear in a persistent and instinctive way either you like them or not and normally they follow a negative pattern. It is like a mental channel you are hearing day in and day out, telling always the same story about you, your present and future life. 
If the content of your mental channel is nice obviously you will feel fine, but when you are tuning a cheerless one your emotions will be set on the corresponding level of suffering. According to the amount, the frequency and the darkness of the content your will feel worse and also may be convinced that you just can't stop thinking this way. From Cognitive Psychology we call this: Automatic Negative Thoughts (ANT) and you will recognize them because they are repetitive, negative and persistent.

The automatic negative thoughts are sustained by beliefs that always lead to the same direction even though if it does not fit with your vital goals, it is emotional insane and sabotage your actions. What people do not know is that this is only a cognitive habit that appears automatically just because we haven't done anything to change it. A baby has not irrational beliefs but as we grow up we shape our mind with beliefs so strongly installed that we don't even have a doubt that they are true. So if we think that getting divorce is the worse thing that could happen to us we will automatically produce a chain of automatic negative thoughts trying to make our belief reliable. Then it is easy to develop feelings of failure versus the own capacity to improve both our emotions and behavior, losing the hope to change and damning our-selves for it.

To overcome the addiction to automatic negative thoughts it is necessary to start becoming aware of every time our brain speaks to us in certain way and became aware that not everything we are hearing from our mind is true. If minds are simply what brains $\mathrm{do}^{3}$ we can overcome automatic negative thoughts by using the capacity of self-reflection, it is developing the ability to think about one's own thinking. One of the main psychological problems in this century is that we are confused about this important distinction: it is not about thinking a lot but thinking about what we think when we think too much.

\section{Acknowledgements}

None.

\section{Conflict of interest}

The author declares no conflict of interest.

\section{References}

1. Albert Ellis. The Myth of Self-Esteem: How Rational Emotive Behaviour Therapy Can Change Your Life Forever. New York, USA: Prometheus Books; 2005. 344 p.

2. Dryden Windy. Dealing with Emotional Problems. Using Rational-Emotive Cognitive Behaviour Therapy. Routledge, UK: A Practitioner's Guide, Hove; 2012.

3. Ray Kurzweil. How to Create a Mind: The Secret of Human Thought Revealed. New York, USA: Viking Books; 2013. 